\title{
VIRTUAL BRAINSTORMING AND CREATIVITY: AN ANALYSIS OF MEASURES, AVATARS, ENVIRONMENTS, INTERFACES, AND APPLICATIONS
}

\author{
Gong, Zhengya (1); \\ Nanjappan, Vijayakumar (1); \\ Soomro, Sohail Ahmed (1,2); \\ Georgiev, Georgi V. (1) \\ 1: Center for Ubiquitous Computing, University of Oulu, Finland; \\ 2: Electrical Engineering Department, Sukkur IBA University, Pakistan
}

\begin{abstract}
How to enhance creativity, especially by applying new technologies to creativity methods, is a question posed continuously by researchers. One reason for this is that creativity is an important part of people's daily lives and an essential component of society. Therefore, many methods to enhance creativity have been created, especially brainstorming, which is one of the most popular and effective tools that inspire individuals to generate ideas, hence enhancing creativity. Moreover, technologies, such as virtual reality (VR), provide an opportunity for individuals and groups to be creative. In response, recent studies have adopted VR in brainstorming to enhance creativity. However, there is a lack of systematic analysis of experimental approaches and creativity measures employed in this context. Addressing this question, this study categorized existing articles on the topic related to categories of avatars, environments, interfaces, or applications. The findings elaborate on trends, measures employed to evaluate creativity and idea generation, identified categories, and results of these studies.
\end{abstract}

Keywords: Virtual reality, Creativity, Design methods, Brainstorming, Idea generation

\section{Contact:}

Gong, Zhengya

University of Oulu

Ubiquitous Computing (UBICOMP)

Finland

zhengya.gong@oulu.fi 


\section{INTRODUCTION}

Creativity is related to various research fields that contribute to the individual and social development (Borgianni et al., 2017). For individuals, creativity is the ability to solve problems in their studies, work, and daily life. In terms of social development, creativity could result in scientific findings, promoting the development of the society, and providing a better life for citizens. Creativity is vital to designers in the design field. Creativity could drive designers to generate ideas and create more novel and useful products, such as optimised mechanical designs (Yu and Colton, 2017), or new products that support the mechatronic development process (Goevert et al., 2017). According to the componential theory of creativity, creativity can be influenced by domain-relevant skills, creativity-relevant processes, task motivation, and surrounding environment. Creativity-relevant processes include skills in generating ideas (Amabile, 2011), which implies that, when we improve effective creative techniques or skills in ideation, creativity-relevant processes can be positively affected, thereby enhancing the creativity. Regarding ideation, brainstorming is one of the most popular creative techniques designed by Alex Osborn in 1953, which is a creative discussion for producing a checklist of ideas that can be evaluated and processed further. He proposed four central guidelines: criticism is ruled out, freewheeling is welcomed, quantity is wanted, combination and improvement are sought (Osborn, 2012).

Virtual reality (VR) is a high-end user interface that involves real-time simulation and interaction through multiple sensory channels (vision, sound, touch, smell, taste) (Burdea, 1999), including immersive VR and non-immersive VR, which adopted in different fields (Georgiev et al., 2021; Georgieva and Georgiev, 2020, 2019). Immersive VR is described as a computer-simulated stage wherein users can interact with an immersive virtual environment (VE) using special electronic equipment, such as a head-mounted display and/or gloves fitted with sensors in a virtual space (Burdea and Coiffet, 2003; Gong and Georgiev, 2020). Non-immersive VR refers to using a desktop or laptop screen to show the users the three-dimensional (3D) VE (Georgiev et al., 2021).

In the past 20 years, the use of VR to enhance the creativity has been far from new. Many researchers have continued to explore the benefits of using VR in concept generation to enhance the creativity (Abdelhameed, 2014; Gong and Georgiev, 2020; Hu et al., 2020; Hu and Georgiev, 2020). For example, Abdelhameed, (2014) verified that using VR helps the later phases of designing instead of the initial phases and has a positive effect on the individual's creativity performance. Hu and Georgiev identified the advantages of employing VR in the early design stage, such as enhancing the users' understanding and promoting design equity (Hu and Georgiev, 2020). Likewise, other researchers reviewed examples of how VR has been used to enhance the creativity in recent years. They proposed a hypothesis that the VR technology can simulate the nature to enhance the creativity (Gong and Georgiev, 2020).

Other researchers have focused on a specific research field, using VR in brainstorming to improve the creative performance and enhance the creativity. Although numerous studies have verified that brainstorming is a useful method to generate ideas and improve the creative performance, some effects during brainstorming, such as social anxiety (Camacho and Paulus, 1995), production blocking (Diehl and Strpebe, 1987), and social loafing (Shepperd, 1993) could negatively affect brainstorming outcomes. With the development of technology, many researchers have reported that virtual brainstorming can decrease negative effects, improve the creative performance, and enhance the creativity (Bonnardel et al., 2016; Guegan et al., 2016). For example, the same VE has been designed based on different technologies (VR and mixed reality (MR)) in brainstorming and the positive effects of VR and MR in enhancing the creativity have been compared (Hwang et al., 2020). Other authors compared oral and written communications in virtual brainstorming, and determined oral communication led to more numerous and original ideas (Forens et al., 2015).

To the best of our knowledge, no studies have summarised the trends and advantages of virtual brainstorming of ideation to enhance the creativity. Therefore, this paper presents an analysis of existing research by the following research question: What are the trends, categories, measures evaluating the creativity and idea generation, and studies investigating virtual brainstorming for enhancing creativity? 


\section{RESEARCH METHOD}

To address this research question, we conducted an initial scan of academic literature related to VR, brainstorming, and creativity in August 2020, focusing on general fields instead of a particular area. The literature search included keywords composed of "virtual reality" \& "creativity" \& "brainstorming" in journal databases, such as Scopus, Web of Science, EBSCO database, IEEE Xplore, and ACM Digital Library. In the first scan phase, we identified and retrieved 65 research articles. While reviewing these articles, we identified two relevant articles that were not retrieved through our keywords. We then articulated the inclusion and exclusion criteria for our study. We included papers that met the following criteria: (1) the full text of the article should be available, (2) the article is published in a journal, as a conference paper, or as an eBook, (3) the study should be a case study, empirical study, experimental study, or comparative study, and (4) the article includes all selected keywords or search terms. We further excluded the papers that matched one of the following criteria: (1) the articles not written in English, (2) only mentioned one or two of the selected keywords or search terms, and (3) the study discussed in the article did not include any experiments, as we aimed to compare the difference between virtual brainstorming and physical brainstorming or influences of different VEs in enhancing the creativity. Therefore, we focused on articles based on experiments. By applying these two inclusion and exclusion criteria, the first author identified 15 articles for the study, and other co-authors confirmed the classification. Figure 1 illustrates an overview of our method for the search and screening processes.

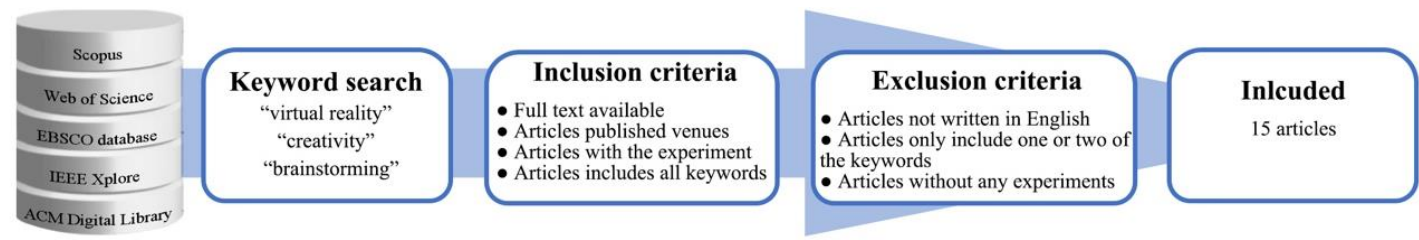

Figure 1. Flow diagram of our search and screening process

\section{RESULTS}

In this section, we summarise the trends, creativity measures, and identify the categories of studies based on a literature analysis. We identified 2013 as the year in which researchers started to using VR in brainstorming to enhance the creativity. Thus, we included only the period of 2013 to 2020 in the review.

\subsection{Research Trends and Sample}

Initially, we examined the bibliometric data of the 15 included papers. The first paper was published in 2013 by Bhagwatwar, Massey, and Dennis (Bhagwatwar et al., 2013). They designed VEs to compare the influence of the environment on the collaborative creative performance. In the next two years, two more studies have addressed the importance of using VR in brainstorming to enhance the creativity (Fominykh et al., 2014; Forens et al., 2015). The number of papers published between 2016 and 2020 accounted for $80 \%$ of the total reviewed papers. The categories of avatars, environments, and applications have almost equal shares in the selected papers. However, only one paper focused on interfaces. Four main types of research experiments are used to evaluate the impact of using VR in brainstorming to enhance creativity, according to our literature analysis. (1) Approximately $33 \%$ of the studies either designed an interface or developed an application to further test and compare the effectiveness of the application for brainstorming (Fominykh et al., 2014; Forens et al., 2015; Gonçalves and Campos, 2018; Kut'ák et al., 2019; Petrykowski et al., 2019). (2) Approximately 26.7\% of the papers compared specific elements in VEs, such as the different virtual objects (Minas et al., 2016) or dynamic and static persona (Bonnardel et al., 2016). (3) 20\% of the studies compared specific effects between the VE and real environment (RE) or MR, for example, the same settings in the physical world and the simulated settings in VE (Guegan et al., 2017a). (4) 20\% of the studies compared the different elements (e.g., avatars with or without social identity cues) in both VE and RE (e.g., Guegan et al., 2017b).

One of the papers did not elaborate on the students' background, however they mentioned the participants' age, $M=19.4$ (Forens et al., 2015). Therefore, we deduced that the students attended college or university. Thus, $73.3 \%(n=11)$ used undergraduates as the sample. The rest of the studies, 
$26.7 \%(n=4)$, used a mixed sample with different age groups in the range of 18 to 56 , with related backgrounds shown in Figure 2.

\subsection{Summary of the Experimental Conditions and Results}

In this section, we discuss the conditions of the comparative experiments and the use of VR in brainstorming to enhance the creativity. All papers could be divided into four main topics: avatars, environments, interfaces, or applications (Figure 2).

\begin{tabular}{|c|c|c|c|c|c|c|c|c|}
\hline & \multirow[b]{2}{*}{ Features } & \multirow[b]{2}{*}{ References } & \multirow[b]{2}{*}{ Subjects } & \multirow{2}{*}{$\begin{array}{c}\text { Setups (time, } \\
\text { platform and } \\
\text { communication) }\end{array}$} & \multirow[b]{2}{*}{ Topics } & \multicolumn{2}{|r|}{ Measures } & \multirow[b]{2}{*}{ Results } \\
\hline & & & & & & $\begin{array}{c}\text { Creative } \\
\text { performance }\end{array}$ & Other measures & \\
\hline \multirow{4}{*}{ ? } & $\begin{array}{l}\text { Dynamic } \\
\text { personas }\end{array}$ & $\begin{array}{l}\text { Bonnardel et } \\
\text { al. (2016) }\end{array}$ & 37 participants & $\begin{array}{l}\bullet 25 \text { minutes } \\
\bullet \text { Second Life } \\
\bullet \text { Textual }\end{array}$ & - Reducing traffic jam & $\begin{array}{l}\text { - Fluency } \\
\text { - Originality }\end{array}$ & $\begin{array}{l}\text { - Quality of the collaboration } \\
\text { - Participants' empathy toward } \\
\text { their persona }\end{array}$ & $\begin{array}{l}\text { Dynamic personas may result in higher } \\
\text { fluency, greater originality of ideas, better } \\
\text { cooperation, and more empathy than } \\
\text { static personas. }\end{array}$ \\
\hline & Inventors & $\begin{array}{l}\text { Guegan et } \\
\text { al. (2016) }\end{array}$ & $\begin{array}{l}54 \text { final-year } \\
\text { engineering } \\
\text { students }\end{array}$ & $\begin{array}{l}\text {-15 minutes } \\
\text { - Second Life } \\
\text { - Textual }\end{array}$ & $\begin{array}{l}\text { - Traveling on snow, } \\
\text { sand or water } \\
\text { - A s silent flying public } \\
\text { transportation }\end{array}$ & • Fluency & $\begin{array}{l}\text { - Creative dimension of avatar, } \\
\text { attractiveness of avatars, } \\
\text { deindividuation of avatars, and } \\
\text { presence of avatars } \\
\text { - Self-assessment of creative } \\
\text { performance and fun factor }\end{array}$ & $\begin{array}{l}\text { The higher performance in fluency and } \\
\text { originality of ideas can be observed in } \\
\text { the inventor avatars group. Moreover, } \\
\text { the inventor avatars affect the following } \\
\text { tasks. }\end{array}$ \\
\hline & $\begin{array}{l}\text { Avatars with } \\
\text { social identity } \\
\text { cues }\end{array}$ & $\begin{array}{l}\text { Guegan et } \\
\text { al. (2017b) }\end{array}$ & $\begin{array}{l}72 \text { final-year } \\
\text { engineering } \\
\text { students }\end{array}$ & $\begin{array}{l}\text {-15 minutes } \\
\text { - Second Life } \\
\text { - Textual }\end{array}$ & - New transportations & $\begin{array}{l}\text { - Fluency } \\
\text { - Uniqueness }\end{array}$ & - Social identification & $\begin{array}{l}\text { Avatars with social identity cues could } \\
\text { increase the creative performance. }\end{array}$ \\
\hline & $\begin{array}{l}\text { Creative } \\
\text { avatars }\end{array}$ & $\begin{array}{l}\text { Buisine \& } \\
\text { Guegan } \\
(2020)\end{array}$ & $\begin{array}{l}72 \text { final-year } \\
\text { engineering } \\
\text { student }\end{array}$ & $\begin{array}{l}\text {-15 minutes } \\
\text { - Second Life } \\
\text { - Textual }\end{array}$ & $\begin{array}{l}\text { - Traveling on snow, } \\
\text { sand or water } \\
\text { - A s silent flying public } \\
\text { transportation }\end{array}$ & • Fluency & $\begin{array}{l}\text { - Presence during the virtual } \\
\text { brainstorming } \\
\text { - Perception of the creative } \\
\text { identity of the avatars and } \\
\text { social identification }\end{array}$ & $\begin{array}{l}\text { Creative avatars without social identity } \\
\text { cues lead to higher creative performance } \\
\text { than non-creative avatars without social } \\
\text { identity cues. }\end{array}$ \\
\hline \multirow{6}{*}{ } & $\begin{array}{l}\text { The creativity } \\
\text { priming } \\
\text { environment }\end{array}$ & $\begin{array}{l}\text { Bhagwatwar } \\
\text { et al. (2013) }\end{array}$ & $\begin{array}{l}80 \text { sophomores } \\
\text { and juniors } \\
\text { from business } \\
\text { school courses }\end{array}$ & $\begin{array}{l}\bullet 15 \text { minutes } \\
\bullet \text { Wonderland } \\
\bullet \text { Textual }\end{array}$ & $\begin{array}{l}\text { - Increasing tourism } \\
- \text { Reducing pollution }\end{array}$ & $\begin{array}{l}\text { - Team level idea } \\
\text { generation performance } \\
\text { - Quality of the ideas }\end{array}$ & & $\begin{array}{l}\text { Incorporating creativity priming objects } \\
\text { into the virtual environment could affect } \\
\text { individual cognition, and consequentially } \\
\text { team performance. }\end{array}$ \\
\hline & $\begin{array}{l}\text { Openness of } \\
\text { the virtual } \\
\text { environment }\end{array}$ & $\begin{array}{l}\text { Minas et } \\
\text { al. (2016) }\end{array}$ & $\begin{array}{l}140 \\
\text { sophomores } \\
\text { and juniors } \\
\text { from an } \\
\text { introductory } \\
\text { business course }\end{array}$ & $\begin{array}{l}\bullet 15 \text { minutes } \\
\bullet \text { Wonderland } \\
\bullet \text { Textual }\end{array}$ & $\begin{array}{l}\text { - Increasing tourism } \\
\text { - Reducing pollution }\end{array}$ & $\begin{array}{l}\text { - Number of ideas } \\
\text { - Number of unique ideas } \\
\text { Quality of the ideas }\end{array}$ & & $\begin{array}{l}\text { The openness of the virtual environment } \\
\text { increased idea fluency and creativity } \\
\text { in comparison to the traditional virtual } \\
\text { enviromment without openness. }\end{array}$ \\
\hline & $\begin{array}{l}\text { Contextual } \\
\text { cues } \\
\text { environment }\end{array}$ & $\begin{array}{l}\text { Guegan et } \\
\text { al. (2017a) }\end{array}$ & $\begin{array}{l}135 \\
\text { undergraduate } \\
\text { students }\end{array}$ & $\begin{array}{l}\bullet 10 \text { minutes } \\
\text { • Second Life } \\
\text { - Textual }\end{array}$ & - Using cardboard box & $\begin{array}{l}\text { : Fluency } \\
\text { : Originality } \\
\text { - Flexibility } \\
\text { - Elaboration }\end{array}$ & $\begin{array}{l}\text { - Perception of the environment } \\
\text { - Perceived level of presence } \\
\text { perforsment of creative } \\
\text { permance }\end{array}$ & $\begin{array}{l}\text { The contextual cues environment leads } \\
\text { to a marginal increase in fluency and a } \\
\text { significant increase in originality and } \\
\text { elaboration. Moreover, changing the } \\
\text { task environment led the participants to } \\
\text { explore idea categories in greater depth } \\
\text { instead of producing more ideas. }\end{array}$ \\
\hline & $\begin{array}{l}\text { Contextual } \\
\text { priming } \\
\text { virtual } \\
\text { environment }\end{array}$ & $\begin{array}{l}\text { Bhagwatwar } \\
\text { et al. (2018) }\end{array}$ & $\begin{array}{l}168 \\
\text { sophomores } \\
\text { and juniors } \\
\text { business school } \\
\text { courses } \\
80 \text { sophomores } \\
\text { and juniors } \\
\text { business school } \\
\text { courses }\end{array}$ & $\begin{array}{l}\bullet 15 \text { minutes } \\
\bullet \text { Wonderland } \\
\bullet \text { Textual } \\
1\end{array}$ & $\begin{array}{l}\text { - Increasing tourism } \\
- \text { Reducing pollution }\end{array}$ & $\begin{array}{l}\text { - Number of unique ideas } \\
\text { Breadth of the ideas } \\
\text { - Depth of the ideas } \\
\text { Quality of the ideas }\end{array}$ & & $\begin{array}{l}\text { Individuals generate better quality ideas } \\
\text { and a greater breadth and depth of ideas } \\
\text { in the topic-specific environment or } \\
\text { enriched-creativity environment than in a } \\
\text { traditional virtual environment. }\end{array}$ \\
\hline & $\begin{array}{l}\text { Virtual } \\
\text { environment }\end{array}$ & $\begin{array}{l}\text { Bourgeois- } \\
\text { Bougrine et } \\
\text { al. (2018) }\end{array}$ & $\begin{array}{l}60 \\
\text { undergraduate } \\
\text { phycology } \\
\text { students }\end{array}$ & $\begin{array}{l}\bullet 10 \text { minutes } \\
\bullet \text { Second Life } \\
\text { - Textual }\end{array}$ & - Improving mobility & $\begin{array}{l}\bullet \text { Fluidity } \\
\bullet \text { Originality } \\
\bullet \text { Utility }\end{array}$ & - Creative potential & $\begin{array}{l}\text { The groups in the virtual environment } \\
\text { performed better in terms of fluency and } \\
\text { originality of ideas in comparison to } \\
\text { those in the real environment. However, } \\
\text { at the individual level, only people with } \\
\text { high risk-taking propensity performed } \\
\text { better in the virtual environment. }\end{array}$ \\
\hline & $\begin{array}{l}\text { Virtual } \\
\text { environment }\end{array}$ & $\begin{array}{l}\text { Hwang et al. } \\
(2020)\end{array}$ & $\begin{array}{l}8 \text { subjects from } \\
\text { a university }\end{array}$ & $\begin{array}{l}\text {-Unmentioned time } \\
\text { Unmentioned } \\
\text { platform } \\
\text {-Oral }\end{array}$ & $\begin{array}{l}\text { - Water and energy } \\
\text { sparing }\end{array}$ & & $\begin{array}{l}\text { - Effect of the environment on } \\
\text { participants' creative processes } \\
\text { and outcome }\end{array}$ & $\begin{array}{l}\text { Individuals generated higher scores on } \\
\text { the constructs of creativity in the virtual } \\
\text { reality environment rather than the mixed } \\
\text { reality environment. }\end{array}$ \\
\hline 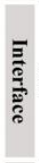 & $\begin{array}{l}\text { Mild place } \\
\text { illusion }\end{array}$ & $\begin{array}{l}\text { Gonçalves } \\
\text { \& Campos } \\
\text { (2018) }\end{array}$ & $\begin{array}{l}16 \text { subjects } \\
\text { ranging in age } \\
\text { between } 21 \text { and } \\
56\end{array}$ & $\begin{array}{l}\bullet \text { Unlimited time } \\
\bullet \text { Haven tool } \\
\bullet \text { Textual }\end{array}$ & $\begin{array}{l}\text { - Nature, food, trips } \\
\text { and holidays }\end{array}$ & & $\begin{array}{l}\text { - Creative behavior inventory } \\
\text { - Concentration, sense of control, } \\
\text { losing track of time, and loss } \\
\text { of self-consciousness } \\
\text { - Participants' opinions about } \\
\text { entire experience, and self- } \\
\text { assessment } \\
\text { - External judging }\end{array}$ & $\begin{array}{l}\text { The mild place illusion user interface } \\
\text { leads to greater self-perception of } \\
\text { creativity than the full illusion user } \\
\text { interface and the user interface without } \\
\text { illusion. }\end{array}$ \\
\hline \multirow{4}{*}{ 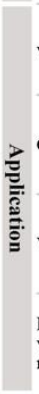 } & vAcademia & $\begin{array}{l}\text { Fominykh et } \\
\text { al. (2014) }\end{array}$ & $\begin{array}{l}40 \text { subjects } \\
\text { from a } \\
\text { university }\end{array}$ & $\begin{array}{l}\text {-Unmentioned time } \\
\text { - vAcademia, } \\
\text { second life } \\
\text { - Textual and oral }\end{array}$ & - Designing an game & & $\begin{array}{l}\text { - Advantages of virtual world for } \\
\text { creative collaboration } \\
\text { - Limitations of virtual world for } \\
\text { creative collaboration }\end{array}$ & $\begin{array}{l}\text { This study's results demonstrated that } \\
\text { there are benefits and limitations of } 3 \mathrm{D} \\
\text { virtual worlds in terms of supporting } \\
\text { creative collaboration. }\end{array}$ \\
\hline & Oral & $\begin{array}{l}\text { Forens et al. } \\
\text { (2015) }\end{array}$ & 66 students & $\begin{array}{l}\bullet 25 \text { minutes } \\
\bullet \text { Second Life } \\
\bullet \text { Textual and oral }\end{array}$ & - Reducing traffic jam & $\begin{array}{l}\text { - Number of unique ideas } \\
\text { Average statistical } \\
\text { originality of the unique } \\
\text { ideas }\end{array}$ & & $\begin{array}{l}\text { Based on the Multi-User Virtual } \\
\text { Environment, oral communication } \\
\text { resulted in more unique ideas and } \\
\text { originality of unique ideas than written } \\
\text { communication. }\end{array}$ \\
\hline & VR Prototype & $\begin{array}{l}\text { Petrykowski } \\
\text { et al. } \\
\text { (2018) }\end{array}$ & $\begin{array}{l}17 \text { subjects } \\
\text { aged around } \\
25 \text {-years-old }\end{array}$ & $\begin{array}{l}\text {-3 minutes } \\
\text {-VR Prototype, } \\
\text { neXboard, } \\
\text { video conference } \\
\text { •Oral }\end{array}$ & $\begin{array}{l}\text { - Places to go or } \\
\text { activities to do }\end{array}$ & - Number of ideas & $\begin{array}{l}\text { Time needed to organize ideas } \\
\text { - Amount of repeated information }\end{array}$ & $\begin{array}{l}\text { Individuals performed better on the } \\
\text { specific design thinking tasks in a } \\
\text { prototype application that they designed } \\
\text { in comparison to the other digital } \\
\text { whiteboards. }\end{array}$ \\
\hline & $\begin{array}{l}\text { Multimodal } \\
\text { virtual reality } \\
\text { mind map }\end{array}$ & $\begin{array}{l}\text { Kutáket al. } \\
\text { (2019) }\end{array}$ & $\begin{array}{l}32 \text { participants } \\
\text { ranging in age } \\
\text { from } 18 \text { to } 33\end{array}$ & $\begin{array}{l}\bullet 10-15 \text { minutes } \\
\bullet \text { Multimodal } \\
\text { virtual reality } \\
\text { mind map } \\
\bullet \text { Oral }\end{array}$ & $\begin{array}{l}\text { - What is best to do on } \\
\text { Friday night }\end{array}$ & & - Usability of the system features & $\begin{array}{l}\text { The study presented a collaborative } \\
\text { multimodal VR mind map application } \\
\text { had a positive impact on interaction, } \\
\text { communication, and collaboration } \\
\text { supporting brainstorming. }\end{array}$ \\
\hline
\end{tabular}

${ }^{2}$ VR glasses background indicates the immersive virtual environment; otherwise, it is a non-immersive virtual environment or not mentioned.

Figure 2. Summary of the features, samples, setups, topics, measures, and results

\subsubsection{Measures to evaluate the creativity and idea generation}

Two types of measures were employed in the reviewed studies: creative performance measures and other measures that might relate to creative performances. Regarding the measurements, $46.7 \%(n=7)$ of the studies evaluated the creativity by combining measurements of creative performance and other measures that might relate to creative performances (Bonnardel et al., 2016; Bourgeois-Bougrine et al., 
2018; Buisine and Guegan, 2020; Guegan et al., 2016, 2017a, 2017b; Petrykowski et al., 2019). Approximately $26.7 \%(n=4)$ of the papers evaluated the creative performance by accounting for the number of ideas and analysing some subdimensions, such as fluency, originality, uniqueness, and novelty (Bhagwatwar et al., 2018, 2013; Forens et al., 2015; Minas et al., 2016). The rest of the studies $(n=4)$ focused on measuring other factors that might be related to creativity, such as the effect of the VE on the participants' creative processes (Hwang et al., 2020), usability of the system features (Kut'ák et al., 2019), the advantages and disadvantages of application (Fominykh et al., 2014), and participants' level of concentration and sense of control (Gonçalves and Campos, 2018), as shown in Figure 2. We adopted the terms from the authors' original works, such as the originality and uniqueness.

\subsubsection{Avatars}

Avatars represent the users who participate in the entire activity in a VE, which influences behaviours through individual identity and social identity cues. During the literature analyses, we found studies that compared (1) the impacts of dynamic, static persona, and without persona (Bonnardel et al., 2016), (2) effects of the inventor avatars and neutral avatars (Guegan et al., 2016), (3) effects of avatars with or without social identity cues (Guegan et al., 2017b); and (4) the effect of creative avatars and avatars with or without social identity cues within VR or not within VR (Buisine and Guegan, 2020). Researchers have continued to explore and compare the different types of avatars, trying to design and select more suitable avatars to be used in brainstorming to enhance the creativity. Bonnardel et al. were inspired by the traditional persona method, which was developed to provide a dynamic persona (represented by an avatar) and static persona (represented by a photo and text), based on a single persona (Kevin, a 21-year-old university student studying psychology that had a detailed set of habits and hobbies. His main fear was to arrive late in class). They then recruited 33 students and divided them into 11 groups (without any persona), and four professionals divided into two groups using dynamic persona or static persona, to participate in the same creative task (reducing traffic jams in a city). Following the tasks, they measured the fluency and originality of the ideas, quality of the collaboration, and participants' empathy towards their persona. The positive effects of dynamic persona emerged in the number of ideas, number of original ideas, quality of collaboration, and empathy related to the individuals' creativity and creative productions (Bonnardel et al., 2016).

Guegan et al. targeted the appearances of avatars and carried out an in-depth comparison research. They designed the inventor avatars based on interviews and feedback from engineering students. The study then evaluated the avatars and selected four inventor avatars (e.g., a scientist wearing a laboratory coat) and four non-inventor avatars. They experimented with three different conditions, in a face-to-face setting, under a neutral avatar condition, and under an inventor avatar condition in virtual rooms in Second Life (same as the face-to-face settings). The following hypotheses were verified: (1) the self-assessed fluency was significantly higher under the inventor condition than under the two other conditions, (2) the subjects under the inventor avatar condition exhibited increased fluency (number of ideas) in the task, and (3) the subjects under the inventor avatar condition exhibited increased originality (number of unique ideas) in the task (Guegan et al., 2016).

Furthermore, Guegan et al. analysed the influence of social identity cues on the groups' creative performance in brainstorming. The experiments included four conditions, brainstorming in a face-to-face setting with social identity cues, brainstorming in a face-to-face setting without social identity cues, brainstorming in a VE with social identity cues, and brainstorming in a VE without social identity cues. The social identity cue is identity that varies along with continuity, involving interpersonal and intergroup behaviour. In this study, the researchers employed their university's traditional clothing, which revealed a strong and positive social identity to induce students' social identity cues. The results indicate that social identity cues resulted in an increased creative performance in face-to-face settings and VE. In contrast, social identity cues only increased the group identification in the VE instead of the other three conditions, which implies that the avatars with social identity cues could improve the groups' creative performance and creative output (Guegan et al., 2017b).

A recent experiment targeting avatars compared proteus and social identity effects. 72 final-year engineering students were involved in the same VE with four different types of avatars (creative avatars with and without social identity cues, and non-creative avatars with and without social identity cues). After brainstorming and collecting data using the questionnaire, the results indicated that (1) the previous exposure to creative avatars increased the creativity in the task, (2) the effects of personal 
identity and social identity interacted with each other, and (3) creative avatars increased the participants' creative performance (Buisine and Guegan, 2020).

\subsubsection{Environment}

Environment refers to VE in this study, which is a computer-generated world in which the user can interact (Burdea and Coiffet, 2003). In the investigation of the use of VR in brainstorming to enhance the creativity, many researchers have focused on designing environments that encourage individuals to perform better in creative tasks.

Bhagwatwar et al. designed two environments based on "priming" (a phenomenon from cognitive psychology where upon individual exposure to one stimulus the following response will be influenced without conscious guidance or intention) to determine whether the VE with creativity priming enhanced the teams' creative performance. One environment included creative priming (such as the presence of plants, windows, and specific dominant colours), whereas the other did not. They recruited 80 sophomores and juniors, randomly divided into 20 groups, to investigate two topics: increasing tourism and reducing pollution. The teams generated a more significant number of ideas in the creativity priming VE and quality of ideas (including novelty, workability, and relevance parameters) was significantly better in the creativity priming VE (Bhagwatwar et al., 2013). Later, Bhagwatwar et al. compared priming in three different types of VE, generic VE, VE with topic-related priming objects, and VE with creativity priming objects. They then conducted brainstorming tasks and investigated which priming objects in a VE would enhance the teams' creative performance. In comparison to the generic VE, the group members produced more unique and better-quality ideas and more categories (breadth) in both VE with topic-related priming objects and VE with creativity priming objects, but only the VE with topic-related priming objects induced a larger category depth (Bhagwatwar et al., 2018).

Similarly, Minas et al. addressed the relationship between priming, attention, and creativity. They proposed that suitable priming can increase the individuals' concentration, thereby improving the performance in comparison to individuals without priming. That study recruited 140 sophomores and juniors from an introductory business course randomly divided into 36 groups. They examined openness in a VE and its effects on the creativity. The findings verified that the team in the open VE (without the visible wall and roof) generated more unique ideas and higher-quality ideas than the team in the closed VE (narrow and closed virtual space with visual walls and roof) (Minas et al., 2016).

Moreover, Guegan et al. emphasised the effect of the VE with contextual cues. They proposed two hypotheses and recruited 135 undergraduate psychology students to brainstorm innovative uses as possible for a cardboard box. To understand the relationship between the contextual cues in the VE and creative process, they studied three settings, (1) a real physical environment, (2) VE similar to the real physical environment, and (3) VE with contextual cues. The hypotheses were partly verified. In a creativity-conducive environment, the participants generated higher originality and elaboration of ideas, whereas the fluency of ideas only marginally increased (Guegan et al., 2017a).

Two articles reported experiments that differed from the studies mentioned above. For example, Bourgeois-Bougrine et al. investigated the relationship between VE and individuals' creative potential. They reported that individuals with a high risk-taking propensity were significantly more creative (fluency and originality) than individuals with a lower risk-taking propensity (Bourgeois-Bougrine et al., 2018). This implied that not all individuals are suitable for virtual brainstorming in comparison to face-to-face brainstorming. Recently, Hwang et al. compared the VR and MR conditions. They employed the Linkography approach to analyse the effect of the environment on idea generation and outcomes. Their results showed that VR achieved higher scores than those of MR in many categories, such as divergence, number of ideas, number of links, and creativity scores. Therefore, they proposed that the level of realism in the environment may affect the ideation. Based on their experiment, they provided two future directions, the effects of a highly stimulating environment and surreal qualities of virtual space, which might positively affect the idea generation (Hwang et al., 2020).

\subsubsection{Interface}

Interface refers to the VR-based user interface. We adopted the terms as in the authors' original study (Gonçalves and Campos, 2018). Although the interface should be included in the application section, the experiment conducted by Gonçalves and Campos needs to be discussed separately, because their experiment only focused on the user interface with different illusions instead of the application design, 
such as functions, tools, or technologies. They introduced a new paradigm, known as the mild place illusion. This study investigated the influences of three writing conditions (control condition without place illusion, mild place illusion condition, and full-level place illusion condition) on the people's self-perceived creativity in writing brainstorming. Particularly, under the mild place illusion condition and full-level place illusion condition, they used the Haven tool (a text processor with an audio soundtrack for inspiration, full-screen mode, and VR landscape), which implies that the only difference between the two conditions is the user interface. They recruited 16 subjects who had already attended creative writing courses, enjoyed writing, or were actual writers, to participate in the writing brainstorming. For the task, Gonçalves and Campos mentioned that "In each condition, participants received a fairytale to read" (Gonçalves and Campos, 2018, p. 3). After that, they had to brainstorm ideas and completed the writing task. All participants completed the self-assessments and post-experiment interviews. Their written data were assessed by external experts from the fields of creative writing, arts, and psychology. The mild place illusion condition resulted in a higher self-perception of creativity in comparison to the full level of place illusion condition and condition without illusion. Moreover, they verified that a mild place illusion interface enabled individuals to generate higher levels of creativity and performance (Gonçalves and Campos, 2018).

\subsubsection{Application}

Application as a VR application in this study is a computer program designed to perform a group of coordinated functions, tasks, or activities for the benefit of the user, which usually contains high-quality 3D graphics (Górski et al., 2016). Although we aim to investigate brainstorming in VEs to enhance the creativity, the experiments conducted by the authors in this section include brainstorming and following tasks, such as voting. We cannot directly separate the brainstorming task and ignore the following tasks because the brainstorming task is integrated into applications and the authors evaluated the effectiveness of the applications. Therefore, we attempted to identify the functions, tools, and technologies of applications, that support brainstorming to improve the creativity performance and creativity.

Fominykh et al. conducted experiments on vAcademia, Second Life, and face-to-face conditions by applying a teaching approach that integrated brainstorming. They summarised several advantages of using these approaches to support collaborative activities (Fominykh et al., 2014). The advantages of using VR to support the creativity were identified from the participants' feedback. For vAcademia, the advantages are the avatars' movements and positions, traces, and changes in the environment, such as pointing tools and chat. Furthermore, each other's sense of presence and spatial awareness was supported. Moreover, vAcademia provides a VE that adds construction and facilities as sources of inspiration, which also supports the creativity. The anonymity of the VE and ability to easily express ideas and provide feedback enabled the participants to be more willing to share their ideas, which could support the creativity.

By a study targeting oral and written communications, Forens et al. demonstrated that the subjects could generate more ideas when they orally communicated in virtual brainstorming. They invited 66 students, divided into 22 groups, to perform a brainstorming task (reducing traffic jams). The results indicated that the subjects in the oral communication groups generated a higher number of unique ideas than that of the subjects in the written communication groups (Forens et al., 2015).

Regarding the comparison of existing software used to perform brainstorming with different conditions or types of communication, Petrykowski et al. designed a prototype to enable collaboration with a whiteboard application to support brainstorming. To support cooperation among the study participants, they compared different interaction paradigms and methods, selected tools, and methods to create others' social presence. The participants brainstormed under two conditions (with or without VR). The results indicated that more ideas generated under VR condition (Petrykowski et al., 2019).

Kut'ák et al. created an application to support interaction, communication, and information-sharing during brainstorming. It provided a canvas with a mind map as a virtual wall for users to input ideas and share them. The main features of the application are as follows. (1) Map nodes with different colours and labels can be moved, deleted, edited, and revised, which can also be connected by lines to represent the relationships. (2) Node selection can be performed by either pressing the nodes or by drawing a shape to select all nodes inside the shape. (3) Voice recognition supports speech-to-text via the Wit.ai service. (4) Voting cannot be closed until all participants cast their vote. According to the participants' feedback, the advantages of this application include immersion, concentration, and 
absence of outside distraction. Moreover, it was funnier than other tools. Although all these benefits could be positive factors in enhancing people's creativity, the study did not measure the creativity or compare the different conditions (Kut'ák et al., 2019).

\section{DISCUSSION}

The reviewed articles summarised four aspects related to the use of VR in brainstorming to enhance the creativity: avatars, environments, interfaces, or applications.

For avatars, the results verified that avatars' dynamic persona, the avatars with individual identity cues, and avatars with social identity could improve the creative performances (Bonnardel et al., 2016; Guegan et al., 2016, 2017b). However, another study indicated that avatars with social identity cues reduced the creative performances (Buisine and Guegan, 2020), which differs from the previous study and needs to be explored further. Moreover, most of the studies recruited subjects from an engineering background. It is better to extend similar experiments in different disciplines to identify whether disciplines affect the choice of creative avatars and whether the choice of creative avatars could improve the creativity of individuals from different disciplines. Furthermore, social identity cues can be extended to companies and organisations, instead of focusing on universities, which could help understand the social identity cues in real teams and improve the creativity, innovation, and competitiveness of companies and organisations.

For environments, most of the studies conducted experiments based on priming: the activation of internal mental representations to influence individuals' behaviours, attitudes, and cognitions (Dennis et al., 2013). Particularly, the experiments conducted by Bhagwatwar et al. and Minas et al. were sustaining to explore the influences of VE with different 3D objects in enhancing the creativity. Based on their studies, the most effective creativity enhancing VE was the topic specific VE, and followed by enriched VE, creative priming VE, and openness VE (Bhagwatwar et al., 2018, 2013; Minas et al., 2016). In addition, only one experiment used a VR headset and controllers. They proposed that the level of realism in the environment might have a positive effect in enhancing the creativity, which might guide researchers to further explore (Hwang et al., 2020).

For interfaces, only one experiment focused on the interface rather than the function, tools, and technologies of application. The authors verified that the mild place illusion user interface led to participants to be more creative and higher self-perception of creativity than the full-level place illusion interface and interface without illusion. Their results are unexpected because a priori is that people should use the full range of illusions as the best setting to enhance creativity (Gonçalves and Campos, 2018). Moreover, the task during time was unlimited and brainstorming was included in the creative writing task. It is unclear whether other effects have any influence on the results.

For applications, when VR is integrated with other techniques, it could encourage individuals and teams to perform better in terms of their interactions, communication, and collaboration. Addressing communication, researchers have identified that oral communication in virtual brainstorming could increase the creative performance, such as more numerous and original ideas (Forens et al., 2015), which can avoid several negative effects caused by written communication, such as interference and cognitive overload (Paulus and Nijstad, 2003). The rest of the research designed applications and tested the effectiveness of the application that integrated other technologies to support brainstorming, thereby improving creative outcomes and creativity (Fominykh et al., 2014; Kut'ák et al., 2019; Petrykowski et al., 2019). However, there are research gaps (e.g., facial expressions and eye contact) that might be explored further. For example, although the application allowed participants to see each other's gestures supporting comprehension and understanding, missing facial expressions could have a negative effect on the comprehension and communication (Petrykowski et al., 2019).

\section{CONCLUSIONS AND FURTHER WORK}

The study presented in this paper summarised 15 articles focused on using VR in brainstorming to enhance the creativity. In this study, we aimed to explore VR trends and focus on virtual brainstorming to enhance the creativity by considering existing studies. Our results confirm that the variety of factors associated with using VR in brainstorming could enable individuals and/or teams to generate more ideas and increase their creative performance. On the contrary, using VR on brainstorming has negative effects to enhance the creativity. For example, wearing head-mounted 
displays led to discomfort, such as motion sickness or nausea, and the low pixel density of head-mounted displays resulted in distraction and dissatisfaction (Kuták et al., 2019).

Although only a few of the reviewed studies devoted specific attention to the application of VR in brainstorming, we believe that an increasing number of researchers will explore research gaps in the future. For example, it might be possible to integrate micro-expression recognition (Li et al., 2021) to capture and recognise facial expressions, and automatically generates them in avatars' faces in VEs. Moreover, the avatar's body size, such as its height, not only affects individuals' behaviours and emotions (Freeman et al., 2014) but also provides unique perspectives to interact with others and VEs (Nishida et al., 2019), which could affect the individuals' creativity. Furthermore, only three studies applied VR devices, which implies that VEs in most of the studies are without highly immersive, and thus it is better to investigate the influence of the immersion in virtual brainstorming to enhance the creativity.

\section{ACKNOWLEDGEMENTS}

This study has been financially supported by Academy of Finland 6Genesis Flagship (grant 318927), and by EDUFI Fellowship (grant TM-20-11342).

\section{REFERENCES}

Abdelhameed, W.A., 2014. Creativity and VR Use, in: Rethinking Comprehensive Design: Speculative Counterculture, Proceedings of the 19th International Conference on Computer-Aided Architectural Design Research in Asia (CAADRIA 2014). pp. 719-728.

Amabile, T.M., 2011. Componential Theory of Creativity. (pp. 538-559). Boston, MA: Harvard Business School. 10. Bhagwatwar, A., Massey, A., Dennis, A., 2018. Contextual Priming and the Design of 3D Virtual Environments to Improve Group Ideation. Information Systems Research 29, 169-185. https://doi.org/10.1287/isre.2017.0721

Bhagwatwar, A., Massey, A., Dennis, A.R., 2013. Creative Virtual Environments: Effect of Supraliminal Priming on Team Brainstorming. Presented at the 46th Hawaii International Conference on System Sciences, IEEE, Wailea, HI, USA, pp. 215-224. https://doi.org/10.1109/HICSS.2013.152

Bonnardel, N., Forens, M., Lefevre, M., 2016. Enhancing Collective Creative Design: An Exploratory Study on the Influence of Static and Dynamic Personas in a Virtual Environment. The Design Journal 19, 221-235. https://doi.org/10.1080/14606925.2016.1129145

Borgianni, Y., Rotini, F., Tomassini, M., 2017. Fostering ideation in the very early design phases: How textual, pictorial and combined stimuli affect creativity, in: Proceedings of the 21 st International Conference on Engineering Design (ICED 17), Vancouver, Canada, 21-25. pp. 139-148.

Bourgeois-Bougrine, S., Richard, P., Lubart, T., Burkhardt, J.M., Frantz, B., 2018. Do Virtual Environments Unleash Everyone's Creative Potential?, in: Bagnara, S., Tartaglia, R., Albolino, S., Alexander, T., Fujita, Y. (Eds.), Proceedings of the 20th Congress of the International Ergonomics Association (IEA 2018). Springer International Publishing, Cham, pp. 1328-1339.

Buisine, S., Guegan, J., 2020. Proteus vs. social identity effects on virtual brainstorming. Behaviour \& Information Technology 39, 594-606. https://doi.org/10.1080/0144929X.2019.1605408

Burdea, G.C., 1999. Haptic feedback for virtual reality. In Virtual reality and prototyping workshop (Vol. 2, pp. 17-29).

Burdea, G.C., Coiffet, P., 2003. Virtual Reality Technology, 2nd Edition | Wiley [WWW Document]. URL https://www.wiley.com/en-us/Virtual+Reality+Technology\%2C+2nd+Edition-p-9780471360896

Camacho, L.M., Paulus, P.B., 1995. The role of social anxiousness in group brainstorming. Journal of Personality and Social Psychology 68, 1071-1080. https://doi.org/10.1037/0022-3514.68.6.1071

Dennis, A.R., Minas, R.K., Bhagwatwar, A., 2013. Sparking Creativity: Improving Electronic Brainstorming with Individual Cognitive Priming. Presented at the 45th Hawaii International Conference on System Sciences (HICSS), IEEE, Maui, HI, USA, pp. 139-148. https://doi.org/10.1109/HICSS.2012.541

Diehl, M., Strpebe, W., 1987. Productivity Loss In Brainstorming Groups: Toward the Solution of a Riddle. Journal of personality and social psychology. 53(3):497., 13.

Fominykh, M., Divitini, M., Prasolova-Førland, E., 2014. Supporting Collaborative Creativity with Educational Visualizations in 3D Virtual Worlds, in: Chiu, D.K.W., Wang, M., Popescu, E., Li, Q., Lau, R. (Eds.), New Horizons in Web Based Learning, Lecture Notes in Computer Science. Springer Berlin Heidelberg, Berlin, Heidelberg, pp. 279-289. https://doi.org/10.1007/978-3-662-43454-3_29

Forens, M., Bonnardel, N., Barbier, M.-L., 2015. How Communication Modalities Can Impact Group Creativity in Multi-User Virtual Environments, in: Proceedings of the European Conference on Cognitive Ergonomics 2015, ECCE '15. Association for Computing Machinery, New York, NY, USA, pp. 1-4. https://doi.org/10.1145/2788412.2788439 
Freeman, D., Evans, N., Lister, R., Abtley, A., Dunn, G., Slater, M., 2014. Height, social comparison, and paranoia_An immersive virtual reality experimental study. Psychiatry Research 348-3525. https://doi.org/10.1016/j.psychres.2013.12.014

Georgiev, D.D., Georgieva, I., Gong, Z., Nanjappan, V., Georgiev, G.V., 2021. Virtual Reality for Neurorehabilitation and Cognitive Enhancement. Brain Sciences 11, 221. https://doi.org/10.3390/brainsci11020221

Georgieva, I., Georgiev, G.V., 2020. Reconstructing Personal Stories in Virtual Reality as a Mechanism to Recover the Self. IJERPH 17, 26. https://doi.org/10.3390/ijerph17010026

Georgieva, I., Georgiev, G.V., 2019. Redesign Me: Virtual Reality Experience of the Line of Life and Its Connection to a Healthier Self. Behavioral Sciences 9, 111. https://doi.org/10.3390/bs9110111

Goevert, K., Baumgartner, M., Lindemann, U., 2017. The agile toolbox - Adaptation of agileMPPs to the mechatronic development process, in: Proceedings of the 21st International Conference on Engineering Design (ICED 17) Vol 4, Vancouver, Canada. pp. 129-138.

Gonçalves, F., Campos, P., 2018. Mild Place Illusion: A Virtual Reality Factor to Spark Creativity in Writing, in: Proceedings of the 36th European Conference on Cognitive Ergonomics - ECCE'18. ACM Press, Utrecht, Netherlands, pp. 1-8. https://doi.org/10.1145/3232078.3232085

Gong, Z., Georgiev, G.V., 2020. Literature Review: Existing Methods Using VR to Enhance Creativity. Presented at the Proceedings of the Sixth International Conference on Design Creativity, The Design Society, pp. 117124. https://doi.org/10.35199/ICDC.2020.15

Górski, F., Buń, P., Wichniarek, R., Zawadzki, P., Hamrol, A., 2016. Effective Design of Educational Virtual Reality Applications for Medicine using Knowledge-Engineering Techniques. EURASIA Journal of Mathematics, Science and Technology Education 13. https://doi.org/10.12973/eurasia.2017.00623a

Guegan, J., Buisine, S., Mantelet, F., Maranzana, N., Segonds, F., 2016. Avatar-mediated creativity: When embodying inventors makes engineers more creative. Computers in Human Behavior 61, 165-175. https://doi.org/10.1016/j.chb.2016.03.024

Guegan, J., Nelson, J., Lubart, T., 2017a. The Relationship Between Contextual Cues in Virtual Environments and Creative Processes. Cyberpsychology, Behavior, and Social Networking 20, 202-206. https://doi.org/10.1089/cyber.2016.0503

Guegan, J., Segonds, F., Barré, J., Maranzana, N., Mantelet, F., Buisine, S., 2017b. Social identity cues to improve creativity and identification in face-to-face and virtual groups. Computers in Human Behavior 77, $140-147$. https://doi.org/10.1016/j.chb.2017.08.043

Hu, X., Georgiev, G.V., 2020. Opportunities with Uncertainties: The Outlook of Virtual Reality in the Early Stages of Design, in: Proceedings of the Sixth International Conference on Design Creativity (ICDC 2020).

Hu, X., Georgiev, G.V., Casakin, H., 2020. Mitigating Design Fixation with Evolving Extended Reality Technology: An Emerging Opportunity. Proc. Des. Soc.: Des. Conf. 1, 1305-1314. https://doi.org/10.1017/dsd.2020.91

Hwang, A.H.C., Sun, Y., McKee, C., Stevenson Won, A., 2020. Real or surreal: A pilot study on creative idea generation in MR vs. VR : Anonymous*. Presented at the 2020 IEEE Conference on Virtual Reality and 3D User Interfaces Abstracts and Workshops (VRW), IEEE, Atlanta, GA, USA, pp. 676-677. https://doi.org/10.1109/VRW50115.2020.00189

Kut’ák, D., Doležal, M., Kerous, B., Eichler, Z., Vašek, J., Liarokapis, F., 2019. An Interactive and Multimodal Virtual Mind Map for Future Workplace. Front. ICT 6, 14. https://doi.org/10.3389/fict.2019.00014

Li, Y., Huang, X., Zhao, G., 2021. Joint Local and Global Information Learning With Single Apex Frame Detection for Micro-Expression Recognition. IEEE Trans. on Image Process. 30, 249-263. https://doi.org/10.1109/TIP.2020.3035042

Minas, R.K., Dennis, A.R., Massey, A.P., 2016. Opening the Mind: Designing 3D Virtual Environments to Enhance Team Creativity, in: 2016 49th Hawaii International Conference on System Sciences (HICSS). IEEE, Koloa, HI, USA, pp. 247-256. https://doi.org/10.1109/HICSS.2016.38

Nishida, J., Matsuda, S., Oki, M., Takatori, H., Sato, K., Suzuki, K., 2019. Egocentric Smaller-person Experience through a Change in Visual Perspective. Presented at the 2019 Conference on Human Factors in Computing Systems, p. 696. https://doi.org/10.1145/3290605.3300926

Osborn, A., 2012. Applied Imagination - Principles and Procedures of Creative Writing. Read Books Ltd.

Paulus, P.B., Nijstad, B.A., 2003. Group Creativity: Innovation through Collaboration. Oxford University Press.

Petrykowski, M., Berger, P., Hennig, P., Meinel, C., 2019. Digital Collaboration with a Whiteboard in Virtual Reality, in: Arai, K., Bhatia, R., Kapoor, S. (Eds.), Proceedings of the Future Technologies Conference (Ftc) 2018, Vol 1. pp. 962-981. https://doi.org/10.1007/978-3-030-02686-8_72

Shepperd, J.A., 1993. Productivity Loss in Performance Groups: A Motivation Analysis. Psychological bulletin 113(1):67.

Yu, S., Colton, J.S., 2017. Mixed-flow irrigation pump design optimization for Bangladesh, in: Proceedings of the 21st International Conference on Engineering Design (ICED 17) Vancouver, Canada, 21-25.08.2017. pp. 071-080. 